\title{
A mechanical sieve for archaeological excavations
}

The following note, by Dr Antonio Guerreschi of the Institute of Geology, Palaeontology and Human Palaeontology of the University of Ferrara, has been translated for us by $D r$ Lawrence Barfield of the Department of Ancient History and Archaeology, University of Birmingham. Dr Barfield has seen this machine in operation on Professor A. Broglio's excavations and says he can vouch for it being a most admirable piece of apparatus which can sieve both wet and dry and is very labour saving. We gladly add it to our 'archaeological aids' corner. It was the brain-child of Dr Guerreschi, and was designed and made by the Campara factory at Cadidavid, Verona.

The sieving of archaeological deposits is a technique which is now widely employed on excavations. The traditional sieving methods have, however, a number of drawbacks which involve both the operation of the sieve and damage to finds. The usual method of sieving is to use a set of sieves with different sized meshes which are hung from supports that allow them to swing. As quite large sieves are needed a considerable output of energy is required if the sieving is to be effective and this uses valuable man power. Another inconvenience, probably more serious, is the damage to fragile objects caused by the sharp jolting when the sieves are pushed. This damage increases in proportion to the length of time the deposit is being sieved. If the sample being sieved is damp, it has to be dried before it can be sieved, which causes delay in processing, and when the sediments are very clayey even this procedure is of little use.

From these observations it is evident that there is a need for a more efficient sieving method which eliminates these disadvantages: this has led to the development of a mechanical sieve.

When dealing with clayey or damp deposits by the traditional sieving methods the sieve mesh tends to become locked and only by combining washing and sieving can this difficulty be overcome. The solution to this particular problem has been to incorporate a washing system into the design of the mechanical sieve, which works during sieving.

In addition, the mechanical sieve is economical of man power since a three-man sieving team, using traditional equipment, can be cut down to one.

\section{Technical details}

The mechanical sieve (PL. $\mathrm{xxx} b$ and FIG. I) consists of a steel supporting framework on which is mounted a crankshaft driven by either an electric motor or a petrol engine. A connecting rod from the crank transmits a reciprocal motion to the sieve vibrator causing a high frequency throw of about $20 \mathrm{~mm}$. The sieves are superimposed and can be easily detached. They measure approximately $90 \times 50 \mathrm{~cm}$. and are $15 \mathrm{~cm}$. deep. The bottom of these sieves is made of stainless steel square mesh with $10 \mathrm{~mm}$. perforations in the upper sieve and $2 \mathrm{~mm}$. perforations in the lower sieve.

The washing system consists of a piped water source, an interrupting tap valve and a series of moveable arms which automatically cut off the water flow when they are moved away from the sieves. The arms are provided with sprays which can cover the whole of the sieves uniformly. In addition a separate water supply is provided through a flexible tube which is connected with a manually operated spray. Finally there is also a system for carrying of the waste from the area of the excavation by means of interconnecting channels.

The total size of the apparatus, including the washing system, is about $40 \mathrm{~cm}$. long, $130 \mathrm{~cm}$. high and $68 \mathrm{~cm}$. wide. Its weight is approximately roo kg.

\section{Testing}

The mechanical sieve has so far been used on three prehistoric excavations: Riparo Tagliente (Verona), Romagnano Loc III (Trento) and Pian del Cavallo (Pordenone). The sediments in these deposits varied considerably in composition from sand at one end of the scale to clay, with many intermediate types of sediment. 'The quantity of finds in these 


\section{NOTES AND NEWS}

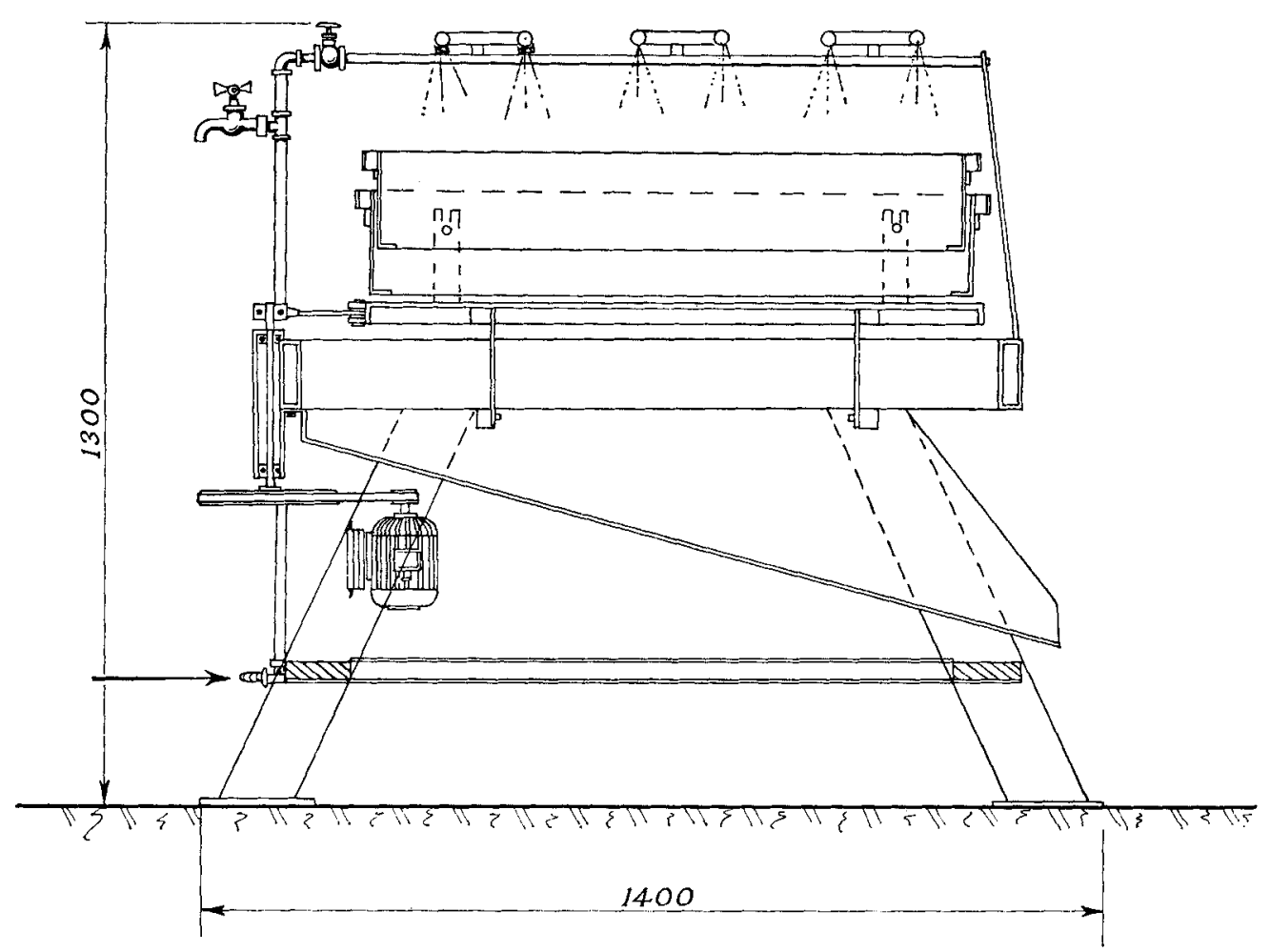

Fig. I. Technical drawing of the mechanical sieve

deposits also varied, so that the testing of the machines was fairly extensive. In sediments with a low clay content the speed of washing and sieving was fast and there were no special difficulties. The process became slower with the increase of the clay content, since the washing took much longer, but in every case it was possible to render the sample being sieved in a

\section{Sediments in archaeology}

A symposium on this subject will take place at Southampton on $15^{-16}$ December I973, jointly organized by Dr D. A. Davidson, Department of Geography, St David's University College, Lampeter, and Miss M. L. Shackley, Department of Archaeology, Southampton University. The aim of the symposium is to provide an opportunity for people who are interested in the analysis of archaeological sediments to meet for discussion of common suitable condition for the sorting of finds. In no instance was any appreciable damage, caused by the sieve, noticed, even to the most fragile of finds.

In conclusion it can be said that the mechanical sieve is an efficient and safe alternative to the traditional methods of preparing excavation deposits for study.

interests. Since workers in this field come from many different disciplines it is hoped to include papers from geomorphologists, soil scientists and geologists as well as from archaeologists. Abstracts will be circulated in advance. Full details and registration forms will be available in September from $\operatorname{Dr} D$. A. Davidson, Department of Geography, St David's University College, Lampeter, Cardiganshire, Wales. 